\title{
Reflexões sobre a segregação das mulheres na educação no Brasil
}

\author{
Maria Inez Barboza Marques ${ }^{1}$
}

\begin{abstract}
Resumo
O texto tem como objetivo refletir sobre a educação formal no Brasil em seu curso histórico e a segregação das mulheres nesse contexto. Foi realizada pesquisa bibliográfica a partir de fontes, que tem como direção, a teoria social crítica. Os resultados demonstraram que no Brasil, o acesso à educação formal para as mulheres é recente, e foi permeado por muitas dificuldades. As últimas barreiras legais para a educação das mulheres só foram rompidas com a Lei de Diretrizes e Bases da Educação, em 1971, que atribuiu equivalência entre os cursos secundários. Foi somente a partir de então que o normal secundário deixou de ser discriminado, por ser apenas um curso profissionalizante, e passou a dar acesso ao Ensino Superior.
\end{abstract}

Palavras-chave: gênero; patriarcado; educação.

\section{Reflections on the segregation of women in education in Brazil}

\begin{abstract}
The text aims to reflect on formal education in Brazil in its historical course and the segregation of women in this context. Bibliographic research was carried out from sources, which have as a direction, critical social theory. The results showed that in Brazil, access to formal education for women is recent,
\end{abstract}

1 Docente do Curso de Serviço Social da Universidade Estadual do Paraná UNESPAR/Campus Paranavaí. Assistente Social. Doutora em Serviço Social pela PUC/SP. E-mail: marques@sercomtel.com.br

GT 19 - Sexualidade, gênero e políticas educacionais 
and has been permeated by many difficulties. The last legal barriers for the education of women were only broken with the Law of Guidelines and Bases of Education, in 1971, which attributed equivalence between secondary courses. It was only from then on that secondary education was no longer discriminated against, as it was only a professional course, and started to provide access to Higher Education.

Keywords: gender; patriarchate; education.

\section{Introdução}

É pertinente iniciar o texto, mencionando Carvalho (1999), quando pondera que, ao pensar a partir da categoria gênero ${ }^{2}$, é possível entender as relações entre homens e mulheres em diversos âmbitos, mas especialmente na cultura, no simbólico e nas representações. Compreender isso é fundamental quando se pensa em educação, porque nesse universo são reconstruídos a cultura, os valores, os símbolos para as novas gerações. Essa dinâmica vai se transmitindo, recriando, reproduzindo ou também transformando as hierarquias, as várias diferenças atribuídas socialmente àquilo que é associado ao masculino e ao feminino. Nesse sentido, a categoria gênero contribui para a compreensão das relações de poder que vão se erigindo e se cristalizando através de diferentes contextos, inclusive e especialmente na educação.

Para desmistificar a divisão sexual do trabalho no contexto da educação brasileira, é necessário compreender como esse fenômeno foi se construindo e enraizando gradativamente em um processo histórico de longa data. A exclusão das mulheres no processo educacional pode ser vislumbrada a partir da colonização do Brasil, que deixou marcas

\footnotetext{
2 Em termos gerais, gênero é apreendido como categoria de análise que trata das relações sociais e culturais construídas entre os sexos e é portador de dimensões teórica e política. Deve ser compreendido também como categoria de análise que vai se desenvolvendo através das teóricas e pesquisadoras envolvidas com o debate e com a luta pela equidade nas relações de gênero (entre homens e mulheres), que são entendidas como relações de poder.
} 
de uma sociedade patriarcal, machista, sexista, racista, que mantém a divisão: gênero, classe, raça/etnia e sexualidade.

\section{Fundamentos para reflexões sobre as desigualdades entre homens e mulheres na sociedade brasileira}

Partindo da perspectiva dialética de leitura da realidade é possível afirmar que o discurso competente, construído no capitalismo, tem como uma de suas bases a ideologia patriarcal que supervaloriza os homens e desvaloriza as mulheres. Nesse sentido, o discurso competente é validado na sociedade que o concebe como legítimo, apesar de se constituir em uma construção social.

O discurso competente confunde-se, pois, com a linguagem institucionalmente permitida ou autorizada, isto é, um discurso no qual os interlocutores já foram previamente reconhecidos como tendo direito de falar e ouvir, no qual os lugares e as circunstâncias já foram predeterminados para que seja permitido falar e ouvir e, enfim, no qual o conteúdo e a forma já foram autorizados segundo os cânones de sua própria competência (CHAUÍ, 2011, p. 19).

É importante ponderar que, além da herança patriarcal, o discurso, em sua forma clássica, é burguês, legislador, ético e pedagógico, na concepção de Chauí (2011 |). A autora afirma:

Por essa via, o discurso nomeava os detentores legítimos da autoridade: o pai, o professor, o patrão, o governante, e, consequentemente, deixa explícita a figura dos subordinados e a legitimidade da subordinação. Emitia conhecimento sobre a história em termos de progresso e continuidade, oferecendo, com isto, um conjunto de referênciais seguras fixados no passado e cuja obra era continuada pelo presente e acaba no futuro. Era o discurso da tradição e dos moços, isto é, o discurso que se 
endereçava aos ouvintes diferenciados e unificados pela unidade da tarefa coletiva herdada (CHAUÍ, 2011, p. 22).

Por esse ângulo, ao refletir sobre as relações sociais, ampliando a compreensão para as relações sociais entre homens e mulheres, expressas na divisão social do trabalho e consubstanciadas na divisão sexual do trabalho, exige-se também uma compreensão da sociedade burguesa em seu movimento histórico, que condiciona as práticas e os discursos na sociedade capitalista de acordo com suas diretrizes e propósitos. No Brasil, essas expressões permanecem enraizadas.

Ianni (2004), ao abordar o processo histórico do Brasil, enfatiza que na sociedade brasileira prevaleceu a continuidade do modelo colonial, com resquícios do escravismo e do absolutismo. Acrescenta que o modo pelo qual o Estado nacional foi se organizando propiciou a continuidade do conservantismo, das estruturas sociais herdadas do colonialismo e do lusitanismo ${ }^{3}$. Aliás, o autor lembra que ao longo do século XIX, período do império, permaneceu relativamente lusitano.

Segundo Ianni, no final do século XIX o Brasil demonstrava viver ainda no século XVIII.

As estruturas jurídico-políticas e sociais tornaram-se cada vez mais pesadas. Revelaram-se carregadas de anacronismo. Eram evidentes os sinais de uma mentalidade formada nos tempos do colonialismo português. A relação dos setores dominantes e do próprio governo com a sociedade guardava os traços do colonialismo (IANNI, 2004, p. 19).

Nesse sentido, nas relações entre os setores dominantes vigentes e os assalariados predominava insistentemente o patrimonialismo. Esse contexto trazia herança do patriarcado da casagrande e uma brutal violência contra os movimentos populares, tanto do campo quanto da cidade.

3 Costume próprio dos lusitanos ou portugueses, que teve forte influência no Brasil. 
Ianni (2004) pondera que 1922 parece que significou o ano em que o Brasil começou a ingressar no século XX. Para o autor, todos os acontecimentos de 1922 sugeriram no prenúncio de outra época, de outro ciclo da história.

A questão nacional, no entanto, se coloca sempre como desafio, obsessão, impasse ou incidente. Havia uma preocupação com as diversidades regionais, étnicas, raciais, acrescidas das sociais, econômicas e políticas. Ocorre uma inquietude pelo fato de a maior nação católica do mundo flutuar sobre a religiosidade afro e indígena.

Além de tudo, Ianni (2004) enfatiza que, logo depois, a Revolução de 1930 provocou uma precipitação advinda das potencialidades, das crises e controvérsias herdadas de um passado (tão presente). Foi exatamente nesta década, de 1930, que se formularam as interpretações do Brasil moderno.

As continuidades e inovações fundamentais foram escritas e publicadas por Florestan Fernandes, Celso Furtado, Antonio Candido e outros que tentavam retratar esse período (Ianni, 2004).

Segundo o autor, a década de 1930 não foi um marco zero, mas criou-se uma atmosfera nova, diferente, de ampla ebulição política e cultural, gerando um fecundo debate sobre a formação e as perspectivas da sociedade brasileira. Mas, mesmo assim, esclarece que nessa década:

Os prenúncios do Brasil moderno esbarravam em pesadas heranças de escravismo, autoritarismo, coronelismo, clientelismo. As linhas de castas, demarcando relações sociais e de trabalho, modo de ser e pensar, subsistiam por dentro e por fora das linhas de classes em formação. O povo, enquanto coletividade de cidadãos continuava a ser uma ficção política. Ao mesmo tempo, setores do pensamento brasileiro vacilavam em face de inclinações um tanto exóticas e demoravam-se para 
encontrar-se com a realidade social brasileira (IANNI, 2004, p. 33).

Ianni(2004) destaca que Gilberto Freyre, com uma interpretação do pensamento moderno europeu e norte-americano, analisou as instituições, formas sociais, familiares, etiquetas sociais e outros. Segundo ele, Gilberto Freyre "focaliza a família patriarcal como se fosse uma miniatura da sociedade, de tal modo que o patriarca aparece como se fosse uma metáfora do governo, e o patriarcado, do poder estatal". Nesse sentido, "as relações e os movimentos de grupos, castas ou classes diluem-se nas relações entre os componentes da família patriarcal" (IANNI, 2004, p. 41).

Concordando com Ianni, é relevante lembrar que, "na interpretação marxista da sociedade brasileira, lida-se principalmente com as relações, os processos e as estruturas que constituem as configurações sociais da vida" (IANNI, 2004, p. 51).

Ianni (2004) reflete ainda sobre a interpretação de Caio Prado Júnior sobre a formação social brasileira, lembrando que tal formação tem privilegiado três processos fundamentais que caracterizam o Brasil contemporâneo. Esses processos revelam que o presente, de fato, está articulado ao passado próximo e remoto e podem ser sintetizados assim: "o sentido da colonização, o peso do regime de trabalho escravo e a peculiaridade do desenvolvimento desigual e combinado" (IANNI, 2004, p. 54).

O autor considera que a escravatura foi a única coisa de fato organizada no contexto da sociedade colonial, por isso adentrou o século XIX. Lembra que foram séculos de escravatura que determinaram a organização do trabalho, da vida, da política e da cultura. Nesse sentido, os séculos de trabalho escravizado geraram e produziram um universo estimável de valores, padrões, ideias, doutrinas, modos de ser, de pensar e de agir. 
Para Ianni, "O desenvolvimento desigual e combinado caracteriza toda a formação social brasileira, ao longo da colônia, império e república" (IANNI, 2004, p. 59).

As reflexões levam à compreensão de que, na história da sociedade brasileira, desde a independência, a questão racial representou e ainda representa uma questão de suma importância para a formação de um povo e da sua cultura. Assim, os que procuram compreender as peculiaridades da sociedade brasileira em seus diferentes momentos se defrontam com a problemática racial, configurada de diferentes formas.

Indianismo, europeísmo, arianismo, lusitanismo, democracia racial, negritude, indigenismo, entre outros, são temas que expressam orientações de pesquisas e controvérsias o significado das raças e mesclas de raças na formação da sociedade nacional (IANNI, 2004, p. 115).

Gadotti (2010) reflete sobre as diversidades no contexto brasileiro e lembra que vivemos hoje uma época de verdadeira explosão das diferenças, sejam elas étnicas, culturais, sexuais e outras. Essas diferenças colocam em xeque a questão do resgate da identidade. Cada vez mais é possível questionar quem são e como se construíram os homens e as mulheres nesse processo.

Com todas as marcas impregnadas no processo histórico brasileiro, é salutar ponderar, refletir e reelaborar o pensamento sobre a influência dessas marcas na cultura brasileira.

A cultura não é inocente. Todas as expressões culturais, compreendendo valores e padrões, maneiras de pensar e dizer, modos de viver e trabalhar criam-se e recriam-se na trama das relações sociais. As diversidades e os antagonismos sociais, políticos e econômicos manifestam-se também no âmbito da cultura (IANNI, 2004, p. 144). 
Para além das pontuações de Ianni (2004), Cisne (2014) apresenta questionamentos (e respostas) que contribuem na reflexão sobre a cultura e como existem elementos no seu interior que influenciam nas relações sociais e, particularmente, nas relações sociais entre homens e mulheres.

Agora, cabe-nos perguntar: De onde vem a cultura? Como ela é determinada e produzida? Quem a produz? A cultura, como nos ensina a tradição marxista, possui determinações materiais. Ela é produzida na e pelas relações sociais que estabelecemos, em um terreno marcado pela luta de classes antagônicas. $\mathrm{Na}$ particularidade das 'relações sociais de sexo', como nos lembra Delphy [...] "a construção social dos valores, o masculino e o feminino são as criações culturais de uma sociedade fundada, entre outras hierarquias, sobre uma hierarquia de gênero". As hierarquias e os interesses que elas guardam/atendem, deve, portanto, ser desvelados criticamente para o entendimento dos valores e do que se concebe como feminismo e masculino (CISNE, 2014, p. 94).

A partir do quadro apresentado, é possível refletir sobre o século XXI e afirmar que, no Brasil, continuam em curso as manifestações e consequências das marcas e de todas as heranças que se processaram no interior do país.

Chauí (2001) considera que a sociedade brasileira conserva marcas da sociedade colonial escravista, também chamada de "cultura senhorial", em que predominou o espaço privado sobre o público.

A sociedade que tem esta marca mantém o centro na hierarquia familiar, refletido em diferentes espaços. Nesse contexto, as relações sociais e intersubjetivas são realizadas como relação entre um superior, que manda, e um inferior, que obedece. Por esse ângulo, as diferenças e assimetrias sempre são transformadas em desigualdades que 
"naturalmente" reforçam a relação mando-obediência, que refletem diretamente nas relações de desigualdades entre homens e mulheres.

\section{Segregação das mulheres na educação brasileira}

No cenário brasileiro, a "desigualdade natural" foi sendo construída em um processo gradativo, porém progressivo em diferentes âmbitos. As marcas deixadas desde a colonização, são mencionadas por Gomes (2015), que trata especificamente da educação e da forma como as mulheres foram sendo excluídas desse processo.

A história, com base no patriarcado ${ }^{4}$, naturaliza o poder hegemônico masculino no tempo e no espaço. Assim, é preciso desvendar os mecanismos de naturalização para perceber que as desigualdades entre homens e mulheres passam por construções históricas que vão se alastrando e criando raízes, que necessariamente precisam ser percebidas e enfrentadas.

Uma das hipóteses sobre a masculinidade, por exemplo, no campo da ciência, pode estar relacionada aos processos de socialização diferenciados para meninos e meninas, na aprendizagem.

tal situação evoca os processos de socialização diferenciados, não menos precoce para meninas e meninos, em relação aos processos de aprendizagem e aos comportamentos próprios, tolerados e interditos que podem orientar, na

\footnotetext{
${ }_{4}^{4}$ Reguant (1996) apud Garcia (2011) define o patriarcado como 'forma de organização política, econômica, religiosa, social baseada na idéia de autoridade e liderança do homem, no qual se dá o predomínio dos homens sobre as mulheres: do marido sobre esposas, do pai sobre a mãe, dos velhos sobre os jovens e da linhagem paterna sobre a paterna, $\mathrm{O}$ patriarca surgiu da tomada de poder histórico por parte dos homens que se apropriaram da sexualidade e reprodução das mulheres e seus produtos: os filhos, criando ao mesmo tempo uma ordem simbólica por meio dos mitos e da religião que o perpetuam como única estrutura possível.
} 
sequência, a vida profissional. Em outras palavras, inicia-se na socialização $\mathrm{o}$ processo de distanciamento das mulheres para com a ciência, na medida em que essas são direcionadas às atividades ditas "femininas", prorrogadas na sequência da vida pelas dificuldades e pelos constrangimentos que se colocam nas escolhas entre família, maternidade e carreira profissional (BANDEIRA, 2019, p. 220).

Gomes (2015) esclarece que a exclusão das mulheres na escolarização é presente desde a colonização do Brasil. O objetivo dos jesuítas e da Companhia de Jesus era preparar a elite para o trabalho intelectual, segundo o modelo religioso católico. No entanto, esse processo não incluía homens e mulheres, tendo em vista que o objetivo era que as mulheres deveriam se submeter à igreja e ao marido e recolher-se ao espaço doméstico. Nesse contexto, a instrução das mulheres era realizada em conventos femininos e, esses, só existiam na Bahia e no Rio de janeiro, tendo sido fundados pelas instituições religiosas.

De acordo com Gomes (2015), o processo, por si, excluía a maioria das mulheres, pois o saber ficava condicionado principalmente às condições materiais satisfatórias. A ida ao convento ou a uma instituição simples de recolhimento exigia um dote por parte da família, evidenciando a segregação de classe e raça, pois as mulheres negras e brancas pobres ficavam de fora desse processo. Mesmo as jovens que iam aos conventos tinham como objetivo "aprender a bordar, coser, fazer doces, ler, escrever, contar, um pouco de latim, música e história sagrada".

Gomes (2015) ressalta que uma das primeiras iniciativas para a instrução feminina ocorre somente no século XIX, no período imperial. Em 1827 é instituída a Lei Geral do Ensino, que se restringia apenas às escolas femininas de primeiras letras. Às professoras, havia restrições 
para o ensino da geometria e da aritmética, sendo incumbidas das instruções para as "prendas" que servem à economia doméstica.

Vale ressaltar, de acordo com Gomes (2015), que o Decreto 7.247 de 1879, no seu Artigo 5 ${ }^{\circ}$, tratou do ensino do primeiro e do segundo graus. No primeiro grau, havia disciplinas comuns, mas os conteúdos de costura simples eram específicos para as meninas. No segundo grau, havia disciplinas voltadas somente para os meninos, como economia social e prática manual de ofícios e, para as meninas, noções de economia doméstica.

Nesse contexto, fica evidente a segregação, desde a colonização que excluía as meninas (principalmente as pobres e negras) e priorizava os meninos.

Seguindo esse modelo, é possível considerar que a sociedade brasileira cria, em suas raízes, funções masculinas e femininas no contexto educacional, em que se afirma a divisão social (e sexual) do trabalho, produtivo e reprodutivo. Uma hierarquia que vai se estabelecendo gradativamente. As funções ligadas ao masculino são historicamente mais valorizadas que as que têm relação com o feminino. Formam-se opostos que vão se cristalizando em uma construção progressiva.

Para Gomes (2015), a imagem construída para homens e mulheres, ao final do século XIX e início do XX, atribuía a estes e a estas características físicas, psicológicas, intelectuais e emocionais diferenciadas.

Gomes (2015), esclarece que a educação formal para as mulheres, no Brasil, é recente e foi permeada por muitas dificuldades. Ocorreu em um processo longo até a permissão legal para o acesso geral e irrestrito das brasileiras à educação superior.

As últimas barreiras legais para a educação das mulheres só foram rompidas com a Lei de Diretrizes e Bases da Educação, em 1971, 
que atribuiu equivalência entre os cursos secundários. Foi somente a partir de então que o normal secundário deixa de ser discriminado, por ser apenas um curso profissionalizante, e passa a dar acesso ao Ensino Superior.

Tratando dessa questão sob um olhar mais amplo, Garcia (2011) reflete que as mulheres se encontram, na maioria dos países, em níveis de ensino básico e, ao mesmo tempo, em números inferiores a $50 \%$ no que se refere aos ramos técnicos dos níveis médios.

No contexto do Ensino Superior, as últimas décadas vêm demonstrando um acesso significativo de mulheres nas diferentes áreas, mesmo aquelas consideradas reduto masculino em sua gênese. No entanto, esse aumento do contingente feminino nas diversas áreas, leva à reflexão sobre as mudanças nas formas de acesso às universidades, bem como sobre as relações que passam a ser estabelecidas entre homens e mulheres, nesse cenário em que uma parcela das mulheres, consegue ocupar lugares considerados privilegiados, como a docência no Ensino Superior. No entanto, mesmo nesse contexto "modificado", em que aparentemente existe igualdade de acesso e condições de trabalho para homens e mulheres em alguns espaços, é possível constatar que existem dificuldades. Garcia salienta que, dentro dos mesmos grupos de professorado, são os homens, em sua grande maioria, que ocupam de fato os cargos diretivos e de poder (GARCIA, 2011, p. 241).

Para Cisne (2014), a divisão de poderes entre os sexos não é resultado de uma questão natural. Ou seja, não está vinculada às capacidades físicas tanto dos homens quanto das mulheres. Pelo contrário, essa divisão está vinculada diretamente à "sexuação social", que é respaldada e encontra apoio na divisão sexual do trabalho e também na categorização do sexo.

a categorização que cria grupos antagônicos, opera por meio das relações sociais de sexo, consiste em 
fixar como verdades definições sociais, estabelecendo o que é um homem e o que é uma mulher, o que é ou não trabalho, o que tem ou não valor, o que é ou não produção. Além, é claro, de estabelecer o que é e o que não é socialmente aceitável (DEVREUS, 2011, p. 14, apud CISNE, 2014, p. 92).

Ampliando as reflexões sobre as relações de poder, Dias (2010), Citando Saffioti (1987), esclarece que, embora o patriarcado e o racismo não tenham suas origens no capitalismo, o sistema de dominação/exploração teve sua conformação concreta a partir de então. Esse sistema de dominação/exploração também é responsável pelas injustiças sociais de modo geral: nas relações entre homens e mulheres e entre etnias e classes sociais. Dias ressalta que a fusão do patriarcado com o racismo e o capitalismo é muito bem usufruída pelas classes dominantes, pois, além de consolidar o poder burguês macho, branco e adulto, permite a formulação de condutas que subordinam os trabalhadores e trabalhadoras, mas não se submetem a elas.

Dias (2010, p. 62) argumenta que a divisão sexual do trabalho se constitui em um dos traços das relações de gênero e também como uma das bases da organização econômica da sociedade capitalista.

Por toda parte e sempre, o 'valor' distingue o trabalho masculino do trabalho feminino: produção 'vale' mais que reprodução, produção masculina 'vale' mais que produção feminina (mesmo quando uma e outra são idênticas). Esse problema do 'valor' trabalho [...] induz a uma hierarquia social, sob aparências múltiplas, permanecem imutáveis: o trabalho de um homem pesa mais que o trabalho de uma mulher. E quem, diz hierarquia, diz relação social (HIRATA; KERGOAT, 2003, p. 113, apud Dias, 2010, p. 64).

Deve-se ter claro que as mulheres foram excluídas também no Brasil, inclusive da história escrita, que contabilizou, na maioria das 
vezes, apenas os "atores" do sexo masculino. No entanto, elas estiveram presentes em todos os contextos e se constituíram em atrizes efetivas, intervindo de diferentes formas, ainda que em situação de dominação/exploração.

Ao longo da história, elas (as mulheres) exercem inúmeras profissões (lavradoras, amas de leite, costureiras, benzedeiras etc.), trabalharam exaustivamente para sobreviver, sustentar sua prole, ainda que por muito tempo, sua situação fosse de forçada submissão, o que não significa ausência de resistência. Muitas mulheres realizaram greves e mobilizações contra a exploração do trabalho na fábrica e pela conquista e ampliação do espaço laboral. As barreiras enfrentadas por elas pela conquista do espaço laboral, espaço naturalmente masculino, vão da variação salarial, à intimidação física, à desqualificação intelectual e ao assédio sexual (DIAS, 2010, p.67).

Cabe considerar as marcas da colonização mencionadas por Chauí (2001) e Ianni (2004), pois a família é mantida como central na hierarquia burguesa, refletindo em diferentes espaços sua moral social enraizada na sociedade reacionária, fundada em princípios da "cultura senhorial", em que predomina o espaço privado sobre o público.

A relação estabelecida entre a mulher no trabalho e a moral social configura-se, desse modo, num espaço em que o trabalho feminino representava uma ameaça a sua honra e a destruição da família. [...] De acordo com Gonçalves (2003) tratam-se de estratégias de ocultação da participação feminina e que tem servido para ampliar o fosso entre os seres humanos, fragmentar as lutas, dificultar a igualdade social entre os sexos nas esferas públicas e privadas (DIAS, 2010, p. 67).

Apesar das problematizações e discussões realizadas, Dias (2010) argumenta que a desconstrução do modelo apresentado é uma saída que pode ser vislumbrada pelo conjunto de atores e atrizes que 
compõem essa trama de relações sociais complexas, que só podem ser compreendidas, na concepção desta pesquisadora, através da lente do gênero e da teoria social crítica, que deixam explícitas a divisão sexual do trabalho e suas raízes profundas na sociedade burguesa (machista, sexista, racista) dividida em classe, gênero, raça, etnia e outros.

pela via da desconstrução, reside a possibilidade de visualização de que o poder que aí se insere é exercido em várias direções, pois os sujeitos constituintes dessa dicotomia não são apenas homens e mulheres inertes, passivos, mas homens e mulheres que diferem entre si pela classe, raça, idade (DIAS, 2010, p. 74).

A história é constituída pela intervenção de homens e mulheres), portanto, com histórias de vida diferentes, experiências diversificadas, alegrias, dores, frustrações e, fundamentalmente, uma identidade construída a partir do seu contexto e da sua vida, que é vivida sob as marcas que lhe foram impressas por uma sociedade contraditória em que a riqueza socialmente construída pertence a poucos, mas, o peso da segregação envolve muitos e deve ser reconhecido e enfrentado coletivamente.

\section{Considerações finais}

Existem diferentes caminhos metodológicos que poderiam subsidiar as Reflexões sobre a segregação das mulheres na educação no Brasil, mas, ao optar por compreender como as bases do capitalismo e do patriarcado influenciaram tal segregação, objetivou-se levar a pensar nas possibilidades da desconstrução da cultura que desconsidera o protagonismo das mulheres no processo histórico da sociedade brasileira.

A desconstrução da cultura endrocêntrica (que mantém os homens como centro e desvaloriza os pensamentos e ideias das 
mulheres) exige posicionamentos políticos com princípios claros, pois como escreve Chauí (2011) o discurso, em sua forma clássica, é burguês, legislador, ético e pedagógico.

Reconhecer os limites e possibilidades nesse contexto é salutar, principalmente no contexto da educação formal, que pode ser conduzida a formular propostas pedagógicas que objetivem levar ao reconhecimento das desigualdades socialmente e culturalmente construídas entre homens e mulheres, mas, mais do que isso, levar a construção de uma cultura que considere homens e mulheres em suas diversidades de classe, gênero, raça/etnia e sexualidade.

\section{Referências}

BANDEIRA, Lourdes. A contribuição da crítica feminista à ciência. Revista Estudos Feministas, Florianópolis, v. 16, n. 1, 2008. Disponível em: <https://www.scielo.br/pdf/ref/v16n1/a20v16n1.pdf>. Acesso em: 15 ago. 2019.

CARVALHO, Marília Pinto de. Um olhar de gênero sobre as políticas educacionais. In: FARIA, Nalu et al (Org.). Gênero e Educação. São Paulo: SOF Sempreviva Organização Feminista, 1999.

CHAUÍ, Marilena de Souza. Cultura e democracia: o discurso competente e outras falas. 13. ed. São Paulo: Cortez, 2011.

CHAUÍ, Marilena de Souza. Escritos sobre a universidade. São Paulo: Editora UNESP, 2001.

CISNE, Mirla. Feminismo e consciência de classe no Brasil. São Paulo: Cortez, 2014.

DIAS, Marly de Jesus Sá. Feminização do trabalho no contexto da reestruturação produtiva: rebatimentos da Saúde Pública. - São Luís, 2010. Coleção CCSo. Teses e Dissertações. EDUFMA. 
GADOTTI, Moacir. Pedagogia da práxis. 5. ed. São Paulo: Cortez; Instituto Paulo Freire, 2010.

GARCIA, Carla Cristina. Breve história do feminismo. 1. ed. São Paulo: Claridade, 2011.

GOMES, Márcia Cristina. Ciência e Tecnologia: desiquilíbrios de gênero na educação superior. 2015. 248 f. Tese (Doutorado em Ciências Sociais) - Pontifícia Universidade Católica de São Paulo (PUC-SP), São Paulo, 2015.

IANNI, Octavio. A idéia do Brasil Moderno. São Paulo: Brasiliense, 2004.

MARQUES, Maria Inez Barboza. Divisão sexual do trabalho e suas expressões: reflexões a partir do trabalho docente em Serviço Social na Universidade Estadual do Paraná (UNESPAR). 2015. 297 f. Tese (Doutorado em Serviço Social) - Pontifícia Universidade Católica de São Paulo (PUC-SP), São Paulo, 2015. 